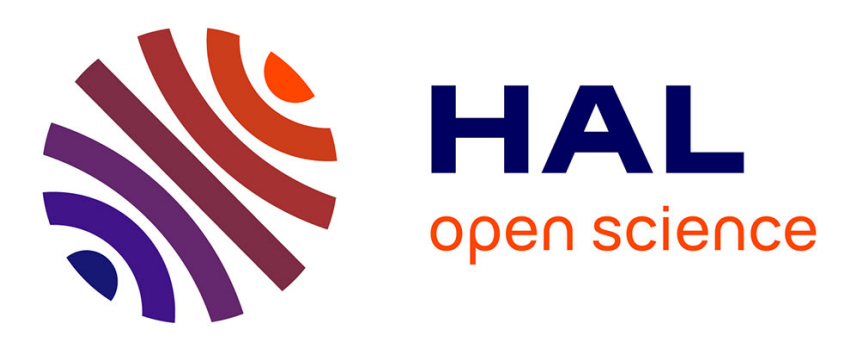

\title{
Non-symmetrical fatigue life of nodular graphite cast iron under non- proportional multi-axial cyclic loading
}

M Kachit, J. Courbon, X. Boulnat, J. Adrien, C. Verdu

\section{To cite this version:}

M Kachit, J. Courbon, X. Boulnat, J. Adrien, C. Verdu. Non-symmetrical fatigue life of nodular graphite cast iron under non- proportional multi-axial cyclic loading. International Journal of Fatigue, 2019, 125, pp.128-137. 10.1016/j.ijfatigue.2019.03.044 . hal-02906567

\section{HAL Id: hal-02906567 \\ https://hal.science/hal-02906567}

Submitted on 29 Jul 2020

HAL is a multi-disciplinary open access archive for the deposit and dissemination of scientific research documents, whether they are published or not. The documents may come from teaching and research institutions in France or abroad, or from public or private research centers.
L'archive ouverte pluridisciplinaire HAL, est destinée au dépôt et à la diffusion de documents scientifiques de niveau recherche, publiés ou non, émanant des établissements d'enseignement et de recherche français ou étrangers, des laboratoires publics ou privés. 


\title{
Non-symmetrical fatigue life of nodular graphite cast iron under non- proportional multi-axial cyclic loading
}

\author{
M. KACHIT, J. COURBON, X. BOULNAT, J. ADRIEN, C. VERDU \\ Université de Lyon, INSA Lyon, MATEIS UMR CNRS 5510, bât. Saint-Exupé- \\ ry, 69621 Villeurbanne cedex, France
}

\begin{abstract}
Non-proportional axial-torsional loading fatigue tests on nodular cast iron revealed a non-symmetrical behavior of the fatigue life relatively to the phase shift angle $\delta=90^{\circ}$ between axial and torsion loads. This behavior was in agreement with fatigue crack orientation investigated using optical and electron microscopy. Elasto-plastic finite element model (FEM) were used to assess the crack orientation behavior and it could explain this non-symmetrical behavior by the non-symmetrical values of both $\sigma_{\text {I }}$ and $\sigma_{\text {I }} / \sigma_{\text {II }}$ ratio relatively to $\delta$ $=90^{\circ}$. FEM revealed that for the $\delta<90^{\circ}$ loads, principal stress was applied essentially at critical planes of low angle $\phi_{n}$, thus occurrence of tensile cracks mode was higher for $\delta<90^{\circ}$ than for $\delta>90^{\circ}$ load, which reduces the fatigue life. $\sigma_{\text {I }} / \sigma_{\text {II }}$ ratio strongly influenced the dominant crack mode. When the applied loads were torsion $\sigma_{\mathrm{I}} / \sigma_{\mathrm{II}}=1$, cracks were observed to occur, equally, in modes I and II. Presence of the nonpropagating failure (mode II) significantly increased the fatigue life. Conversely, for high phase shift, where $\sigma_{\text {I }} / \sigma_{\text {II }}>>1$, crack mode I dominated and crack driving force remained high during the whole fatigue cycle, inducing a lower fatigue limit.
\end{abstract}

Keywords: Multi-axial fatigue life; Phase shift angle; Crack orientation; Principal direction, Cast iron.

\section{Introduction}

Several factors may contribute to the difficulty in predicting the crack orientation and consequently the fatigue life of metals undergoing out-of-phase multi-axial loading. The critical plane concept was based on the physical observations that crack initiate and grow on preferred planes [1-2]._Under proportional cyclic loading, principal directions were fixed in space and did not rotate, so the main stresses change only their amplitude and not their direction. Under non-proportional loading, the directions of maximum normal stresses change continually, which makes other planes go through the maximum stress direction, the fatigue lives were then reduced accompanying by an additional cyclic hardening [3-5]. Consequently, a sequence of Von Mises stresses did not have physical meaning: in one cycle, it had non-zero value in spite of the negative values of applied stresses, so it did not correctly reflect the real load [6]. In order to eliminate this ambiguity, Bishop [7] proposed a correction. According to Bishop, the equivalent stress should be a "signed Von Mises" stress, the sign being generally given by the first principal stress $\sigma_{I}$, as its general form was: $\sigma_{\text {eq,vMs }}(t)$ $=\sigma_{\text {eq, vm }}(\mathrm{t}) \cdot \operatorname{sign}\left(\sigma_{1}(\mathrm{t})\right)$. In this case, due to the rotation of the principal axis, a crack initiated on the critical plane was usually subjected to shear mode loading as well as tensile mode loading. However, when the critical plane coincides with the principal plane, the value of Mode I stress intensity factor (SIF) is at its maximum, whereas the shear stress was equal to zero. Therefore, at the point of loading cycle where the crack was opened widest, the mode I loading condition should be dominant and the crack will propagate as a mode I crack. Therefore, the dispersion of fatigue crack orientation was related to the phase shift between the axial and torsion applied stresses. The proportional loading may provide better results than non-proportional one, that's why it could be used to evaluate the capability of a critical plane approach for predicting the cracking directions [8-11]. The initiated fatigue cracks orientation was more dispersed under non-proportional loading paths. If most of the material planes were experiencing significant fatigue damage, it will be difficult to identify a crack initiation site and direction. This explains the considered scattering in the fatigue experimental data and provides a challenge to fatigue modeling. So, a single criterion itself could not capture the fundamental fatigue mechanism of multi-axial loading.

Another factor contributing to the dispersion of fatigue crack orientation was the effect of material ductility and microstructure. For proportional load, certain materials crack in brittle fashion, or in normal stress (or strain) as 7075-T651 aluminum alloy whose the loading stress is below a certain level [12], S460N steel [13] and FCD700 nodular cast iron [14]. The ductile material crack in shear stress (strain) as Inconel 
718 [15] and cooper [16]; Semi-ductile materials crack with a combination of normal and shear stresses (strains) [17], as 1045 and 1070 steels [18-19] and S35C steel [20]. In this case, cracks are initiated on the maximum normal planes for tension-compression loading but on the maximum shear plane under pure shear loading [21].
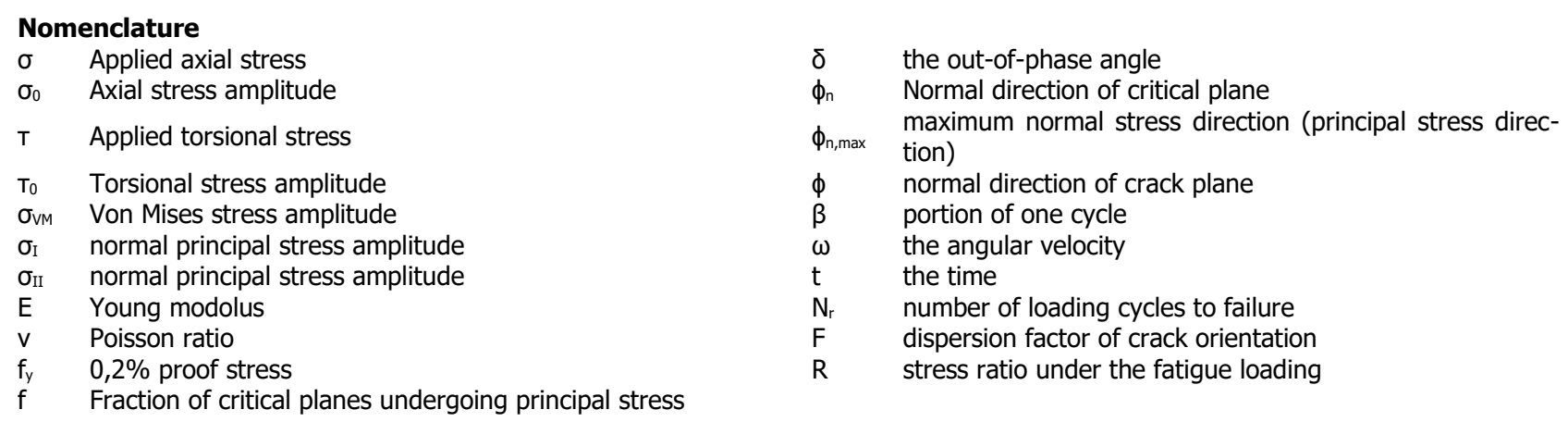

For out-of-phase loading, the fatigue crack will not have a strong preferential direction [22], then its propagation did not stop [21]. In materials as nodular cast iron [23] and AISI316 stainless steel [24] subjected to an out-of-phase multi-axial load, cracks were free to propagate in any direction. For this reasons, in one hand, the fatigue limit in multi-axial load for these materials was lower than what was expected from simple elasticity considerations, and in the other hand, the dispersion of crack orientation was higher, which impedes the fatigue life modeling.

Predicting fatigue crack orientation and therefore the fatigue life, necessitates, in one hand, further understanding of the fundamental fatigue mechanism and cracking mode during multi-axial loading, and in the other hand reducing the dispersion of measurements and calculations of cracks orientation. For this purpose, in the current study, a series of proportional and non-proportional tension-compression and torsion fatigue tests were conducted on nodular cast iron in order to study the fatigue life behavior and the distribu tion of fatigue crack orientation under multi-axial load. Nodular graphite cast iron is a material that fails in uniaxial fatigue cracking behavior by the initiation and growth of mode I crack (brittle material) [23]. Even if this material was regularly studied in the literature, there were limited experimental data about the cracking behavior in the matrix (mode II crack) under multi-axial fatigue loading and about the effect of out-ofphase angle on mode I/mode II cracks proportion and the fatigue life behavior. Despite the dispersion of the crack orientation for multi-axial loading presented in literature, the current study revealed that the fatigue behavior was non-symmetrical relatively to $\delta=90^{\circ}$, where the fatigue life was higher in the range 90 $<\delta<180$ than in the range $0>\delta>90$. A Numerical study based on stress states on the edge of the graphite nodules was proposed to explain the experimental results and determine the behavior of maximum normal stress (its magnitude and direction) in function of multi-axial loading conditions. .

\section{Experiments}

The studied material was a ferritic nodular cast iron obtained after austenitization at $950^{\circ} \mathrm{C}$ for $48 \mathrm{~h}$ then cooling at very slow rate $\left(<0,01^{\circ} \mathrm{C} . \mathrm{s}^{-1}\right)$ according to CCT curves of ductile iron [25]. This treatment allowed to obtain ferrite-graphite-perlite (Fig. 1) structure and prevent the formation of ledeburite and cementite.

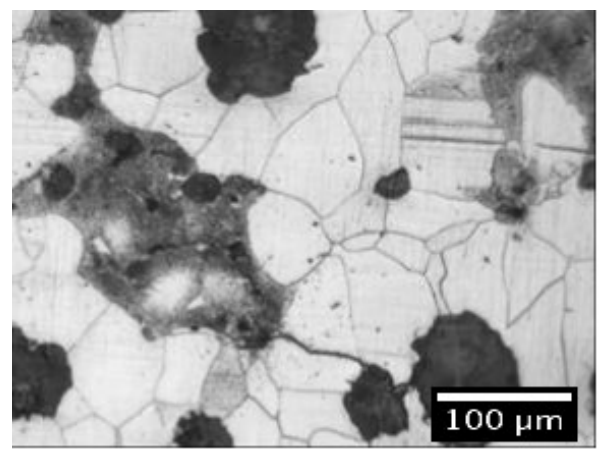

Fig. 1: OM Microstructure of the studied nodular cast iron after heat treatment and etching (Nital $4 \%$ )

Chemical composition is given in Table 1:

Table 1: Chemical composition (wt \%) of the studied nodular cast iron

\begin{tabular}{lllllll}
\hline $\mathrm{C}$ & $\mathrm{Si}$ & $\mathrm{Mn}$ & $\mathrm{S}$ & $\mathrm{P}$ & $\mathrm{Mg}$ & $\mathrm{Fe}$ \\
\hline & \multicolumn{6}{c}{2}
\end{tabular}


Tensile tests were performed on the dog-bone specimen with a gage length of $12 \mathrm{~mm}$ and section of $9 \mathrm{~mm}^{2}$ at a strain rate of $10^{-3} \mathrm{~s}^{-1}$. Tensile properties were found as follows: $\mathrm{E}=168 \mathrm{GPa}$ (direct measurement by a clip gauge), $0,2 \%$ proof stress $\left(f_{y}\right)=270 \mathrm{MPa}$, UTS $=500 \mathrm{MPa}$ and engineering strain at fracture $=17 \%$. The material designation was then close to EN-GJS-400-18. Tensile curve (Fig. 2) was used to determine the elasto-plastic properties for the FEM. Two tensile tests were performed for reproducibility purpose.

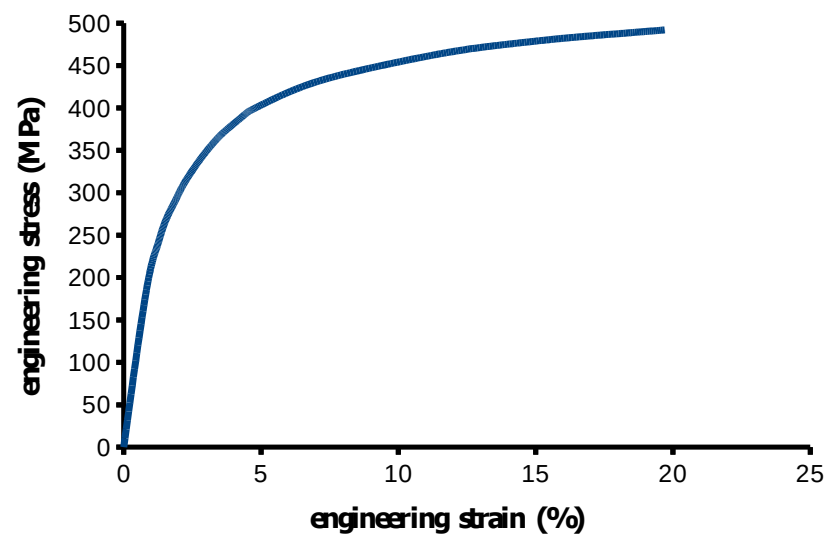

Fig. 1: Engineering stress-strain curve of nodular cast iron specimen

The fatigue specimens were cylindrical (Fig. 3c) with a gage length of $25 \mathrm{~mm}$ and diameter $6 \mathrm{~mm}$. The cylindrical surface was polished with paper grain 2400 (paper grain size $10 \mu \mathrm{m}$ ). Polishing with diamond pastes $3 \mu \mathrm{m}, 1 \mu \mathrm{m}$, and $1 / 4 \mu \mathrm{m}$ lubricated with ethanol was done longitudinally on the gage length to have a flat narrow band $\left(0.5 \times 7 \mathrm{~mm}^{2}\right)$ allowing reliable SEM and in situ optical crack observations. Fatigue tests were conducted under stress-controlled multi-axial cyclic loading using servo-controlled hydraulic testing machine (Fig. 3) that performs tension-compression and torsion simultaneously.

(a)
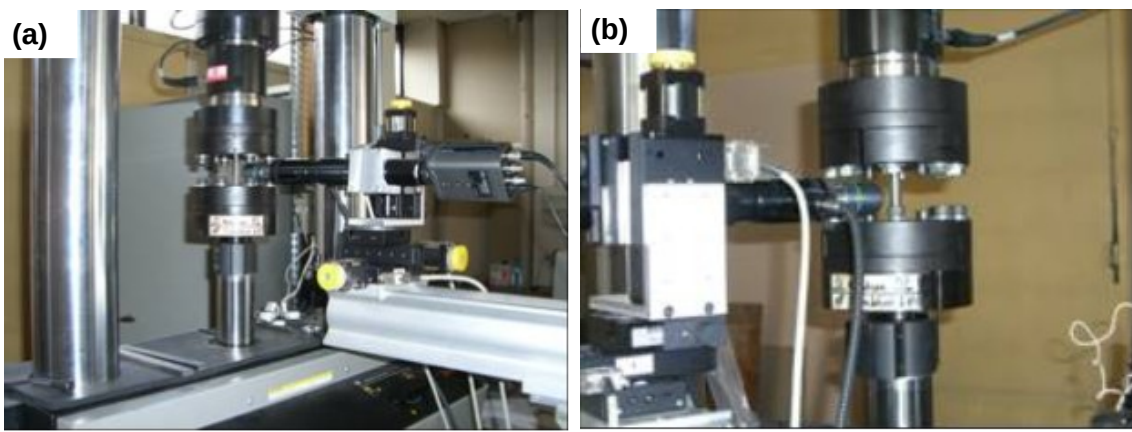

(c)

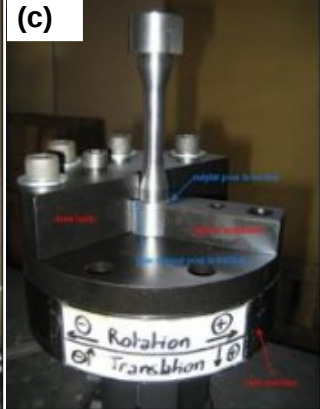

Fig. 1: The servo-controlled hydraulic testing machine ( $a, b$ and $c$ ) equipped with in-situ optical microscope ( $a$ and $b$ )

The variations in applied axial $\sigma$ and torsional $\tau$ stresses under combined loading were expressed by the equations 1 and 2 respectively:

$$
\begin{gathered}
\sigma=\sigma_{0} \sin (\omega t) \\
\tau=\tau_{0} \sin (\omega t+\delta)
\end{gathered}
$$

Where $\boldsymbol{\sigma}_{\mathbf{0}}$ and $\boldsymbol{\tau}_{0}$ were the amplitudes of axial and torsional stresses respectively, $\boldsymbol{\omega}$ : the angular velocity, $\mathbf{t}$ : the time, and $\boldsymbol{\delta}$ : the phase difference between the two stresses (out-of-phase angle).

The tests were conducted at room temperature under controlled Von Mises stress amplitude (EQ. 3), and by varying the phase shift angle $\delta\left(\delta=0^{\circ}, 30^{\circ}, 45^{\circ}, 60^{\circ}, 80^{\circ}, 90^{\circ}, 100^{\circ}, 120^{\circ}, 135^{\circ}, 150^{\circ}\right.$ and $\left.180^{\circ}\right)$. Simple tension-compression and torsion tests were also conducted for comparison. A sinusoidal signal was imposed at a frequency of $10 \mathrm{~Hz}$ and $\mathrm{R}=-1$. Seen that Von Mises criterion results in the same damage for in-phase and $90^{\circ}$ out-of-phase loadings, and on all planes $[17,26]$, the tests were performed in such a way that the axial stress $\boldsymbol{\sigma}$, and the shear stress $\tau$ were equally damaging. According to the Von Mises distortion energy hypothesis (DEH), i.e. the particular amplitudes had the ratio $\sigma / T=\sqrt{ } 2$ because the lifetime for torsion is half of that for axial solicitation.

$$
\sigma_{\mathrm{VM}}=\sqrt{\left(\sigma^{2}+2 \tau^{2}\right)}
$$


Table 2 shows the values of the applied axial and shear stresses and controlled Von Mises stress amplitude according to eq. 1, 2 and 3 definitions:

Table 1: Values of tensile and shear stress applied amplitudes and controlled Von Mises stress amplitude according to eq. 1,2 and 3

\begin{tabular}{|c|c|c|c|}
\hline Load type & tensile stress applied amplitudes (MPa) & shear stress applied amplitudes (MPa) & $\begin{array}{c}\text { controlled Von Mises maximum } \\
\text { stress }(\mathrm{MPa})\end{array}$ \\
\hline simple Axial & 215 & 0 & \multirow[t]{13}{*}{ 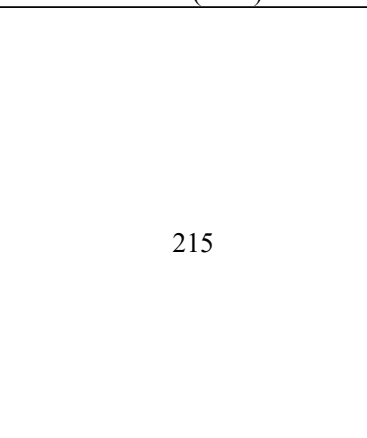 } \\
\hline simple Torsional & 0 & 152 & \\
\hline$\delta 0$ & 152 & 107,5 & \\
\hline$\delta 30$ & 157,5 & 111,4 & \\
\hline$\delta 45$ & 164,5 & 116,3 & \\
\hline$\delta 60$ & 175,5 & 124,1 & \\
\hline$\delta 80$ & 198 & 140 & \\
\hline$\delta 90$ & 215 & 152 & \\
\hline$\delta 100$ & 198 & 140 & \\
\hline$\delta 120$ & 175,5 & 124,1 & \\
\hline$\delta 135$ & 164,5 & 116,3 & \\
\hline$\delta 150$ & 157,5 & 111,4 & \\
\hline$\delta 180$ & 152 & 107,5 & \\
\hline
\end{tabular}

The test was periodically interrupted and fatigue crack orientations were captured with the in-situ optical microscope (OM). Fatigue crack orientation had also been further investigated after rupture using OM and a scanning electron (SEM) microscope.

For the reproducibility of results, two samples had been tested for each loading condition. The following nominations will be used to describe the loading conditions:

- a: axial loading (tension-compression), ex. a1: axial loading for sample number $1, \ldots$ etc

- t: torsional loading.

- $\delta x x x$ : loading with out-of-phase shift angle $x x x^{\circ}$.

- $\delta^{\circ}$ : phase shift between the axial and torsion loads. The studied range was [0-180 $]$ (Fig. 4a).

- $\beta^{\circ}$ : angular portion of the fatigue cycle. The studied range was $\left[0-180^{\circ}\right]$ (Fig. $4 a$ ).

- $\phi^{\circ}$ : the normal direction of the crack plane (fatigue crack orientation) measured relative to the specimen axis (vertical axes). Positive with clockwise, negative counterclockwise. $\phi$ range was $\left[-90\right.$ to $\left.+90^{\circ}\right]$ (Fig. $4 a$ and $b$ ).

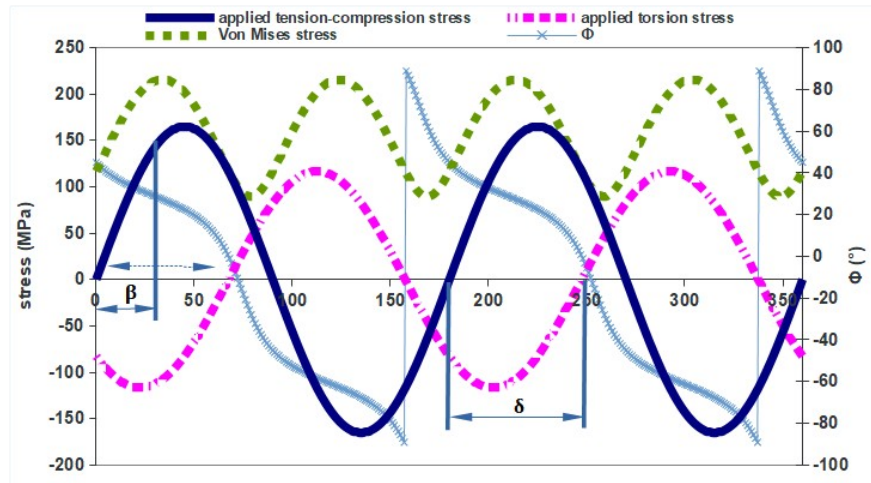

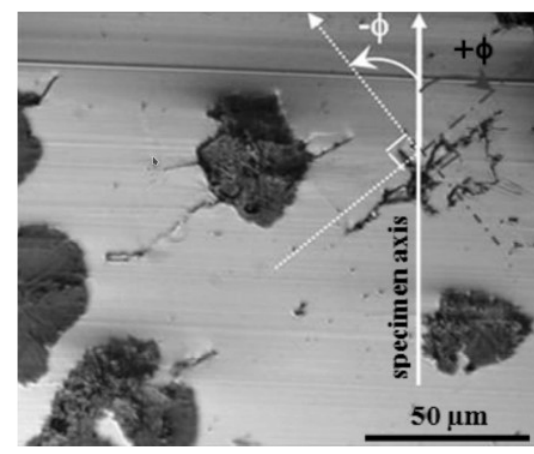

(b)

Fig. 1: (a) Definition of the applied and Von Mises stresses and $\delta, \beta$ and $\phi$ angles during the fatigue cycling for the out-of-phase load 3. Experimental Results (b) Definition of fatigue crack orientation angle (the image was for $\delta 0$ )

\subsection{Graphite nodule properties}

The main characteristics of the graphite nodules were determined by 2D optical microscopy images taken at the flat narrow band before the fatigue tests. The histograms in Fig. $5 a$ and b show the size distribution and the sphericity of the nodules respectively, for three samples (randomly selected). The total number of graphite nodules characterized on the flat surface evolves from 300 to 900 nodules according to the zones and the samples studied. Based on these analyses, the mean values of the nodule size $(20.1 \mu \mathrm{m})$ and of the sphericity (0.53) were determined. 

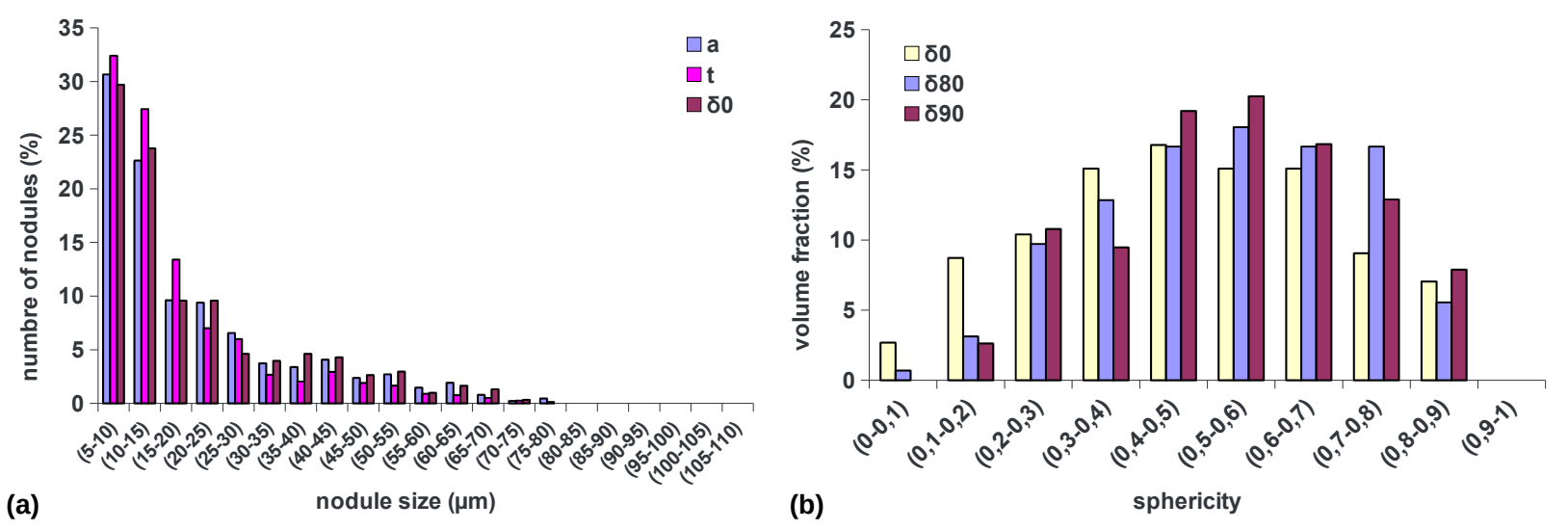

Fig. 1: Distribution of the apparent size (a) and sphericity (b) of nodules

The number of cycles at failure $\left(\mathrm{N}_{\mathrm{r}}\right)$ presented here was determined from three tests per load type. It was displayed against the phase shift angle in Fig. 6a. The error bar was found to be nearly proportional to the measured value (of about: $10 \%$ ). Nr linearly decreased with the phase shift in the intervals $\delta=0^{\circ}-90^{\circ}$ and $\delta=180^{\circ}-90^{\circ}$. It reaches its minimum value (about 40,000 cycles) for $\delta 90$ load; for this latter phase shift angle, $\mathrm{N}_{\mathrm{r}}$ was reduced by a factor of about 10 with respect to $\delta 0$ load. For simple tension-compression load, $\mathrm{N}_{\mathrm{r}}$ (about 600,000 cycles) was 1.2 times higher than for proportional one. Fatigue life reaches the highest value for simple torsion load (about 4,000,000 cycles).

Similarly to results reported in the literature [10] the fatigue life was reducing linearly as long as the out-of-phase angle was approaching the $90^{\circ}$ out-of-phase angle. Contrary to our results, Tovo [27] did not mention a difference of fatigue life between the out-in-phase and in-phase load, and highlighted the "unusual sensibility to the out-of-phase loading". In this study nearly the same material and loading conditions (frequency, mean fatigue stress, out-of-phase and in phase, the same material, nodule size and density) were tested but not the same equivalent applied stress for the in-phase and out-of-phase loads. The applied stresses were different between out-of-phase and in-phase loads, so the two loads did not have the same equivalent stresses or damage effect.
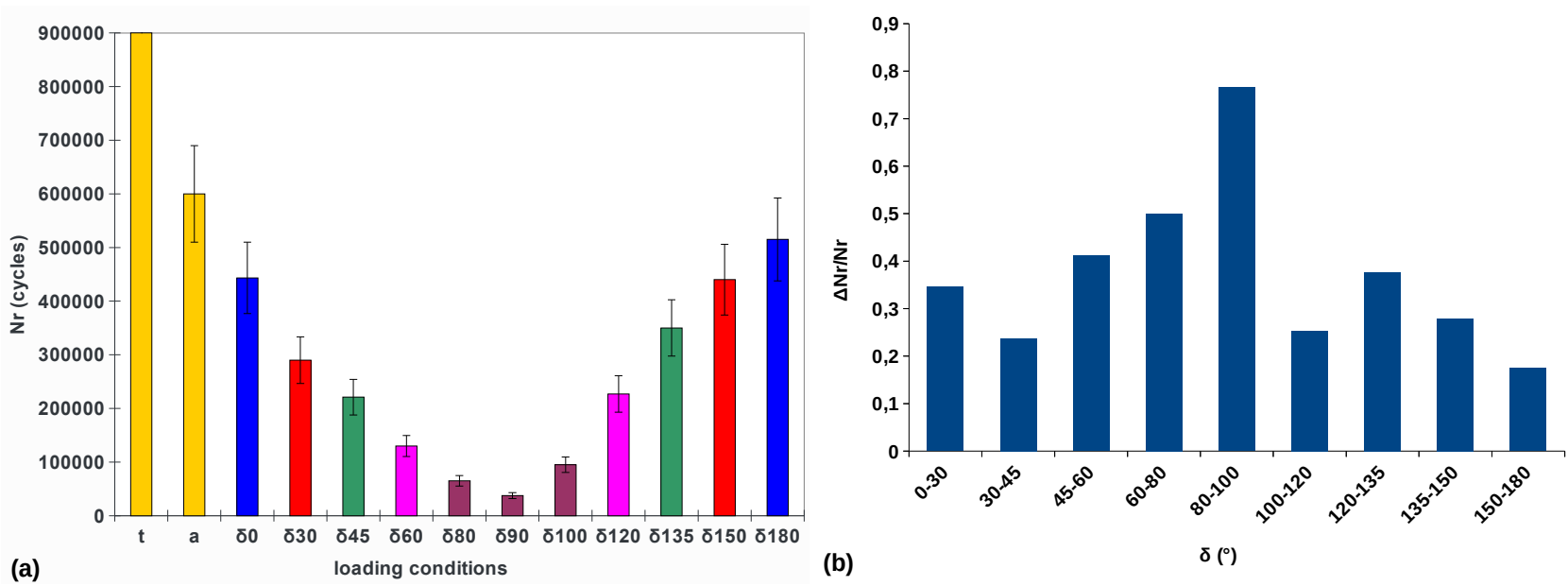

Fig. 1: (a) Effect of loading conditions on the number of cycles at rupture. (b) Ratio $\Delta N_{r} / N_{r}$ versus the out-of-phase angle $\delta$

Unlike results reported in the literature [10], this study highlighted a non-symmetrical behavior of fatigue life relatively to $\delta=90^{\circ}$. The fatigue life was about $50 \%$ higher for phase shifts situated in the range angle $90<\delta<180$ than for their symmetrical angles in the range $0<\delta<90$. These results could not be affected by the uncertainty of measures seen the reproducibility of this behavior between the two investigated symmetric loads which have a significantly different damaging effect. In fact, these results could be explained and confirmed using finite elements method, which revealed a non-symmetrical behavior of $\sigma_{\mathrm{I}}$ and $\sigma_{\mathrm{I}} / \sigma_{\text {II }}$ relatively to $\delta=90^{\circ}$. The relative difference of the fatigue life $\Delta N_{r} / N_{r}$ for each range of out-of-phase angle $\delta$ is reported in Fig. $6 \mathrm{~b}$. Two information could be deducted: firstly, this ratio was higher for the $\delta<$ 90 loads than for $90>\delta$ ones, and secondly, it was as high as $\delta$ was close to $90^{\circ}$. 


\subsection{Distribution of fatigue crack orientation}

The $\phi$ angle of crack orientation was measured between the axis of the specimen and the normal of crack plane (cf. Fig. 4b). Fig. 7a and b show the distribution of crack orientation, i.e. the percentage of cracks having a given orientation. For the reproducibility purposes, the distribution was done for two samples of axial and torsion loads. The uncertainty of results was low seeing the reproducibility of crack distribution orientation curves, as shown for the axial and torsion loads. The uncertainties were then: uncertainty on the crack orientation measures (at the top of the peak) was $\pm 2,5^{\circ}=3 \%$, and Uncertainty on the height of the peak was $\pm 9 \%$.
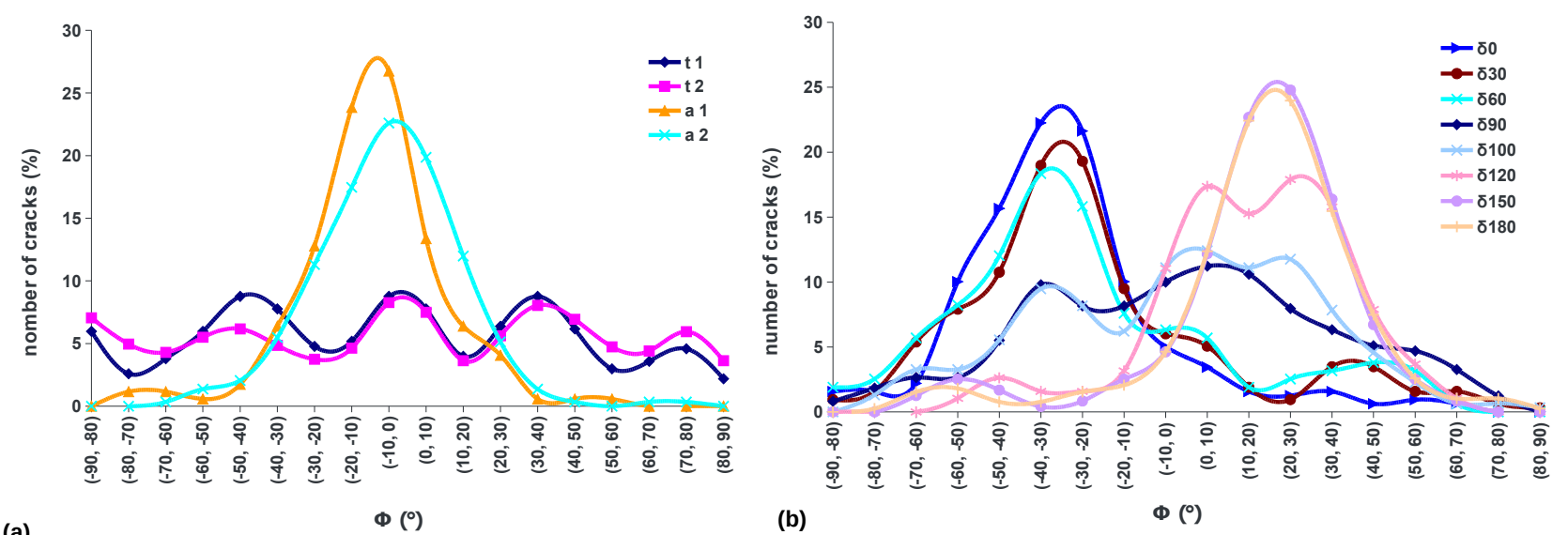

Fig. 1: Distribution of fatigue crack orientation for axial and torsion loads (a) and for in-phase and out-of-phase loads (b).

For axial load (tension-compression), Fig. 7a showed a single peak located in the angular range $\left[-25^{\circ}, 25^{\circ}\right]$, and having a maximum (about $25 \%$ ) at $0^{\circ}$, that corresponded to OM image (Fig. 8a), where cracks are located at nodules and oriented at about $0^{\circ}$. Nearly $70 \%$ of cracks were oriented between $-25^{\circ}$ and $25^{\circ}$, i.e. in mode I crack, outside this range, the percentage of cracks was almost neglected. For simple torsion (Fig. 7a), the distribution showed the presence of four peaks located in equidistant angular ranges; these peaks were of nearly equal width and amplitude. The maximums of these peaks were located at about $-45^{\circ}, 0^{\circ}$, $45^{\circ}, 90^{\circ}$. These orientations were classified into orientations in the matrix (at $0^{\circ}$ and $90^{\circ}$ ) as mode II crack, and orientations at the nodules (at $\pm 45^{\circ}$ ) as mode I crack. Cracks at nodules formed a symmetrical cross (Fig. 8b), where mode I crack driving force was nearly equal in the two directions $\pm 45^{\circ}$. The peaks had maximums of about $8 \%$ and minimums of about $3 \%$. Cracks in the matrix were initiated longitudinally and perpendicularly to the $0^{\circ}$ oriented slip microbands (Fig. $8 \mathrm{c}$ and d respectively).

(a)

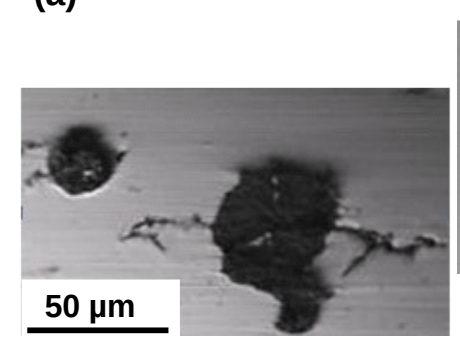

(b)

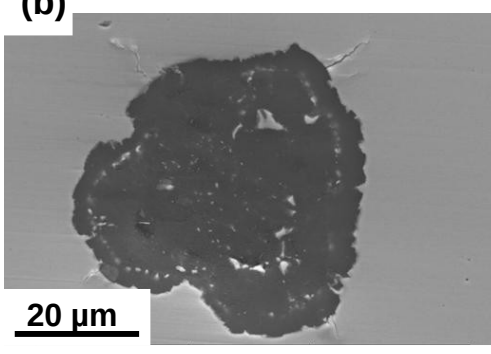

(c)

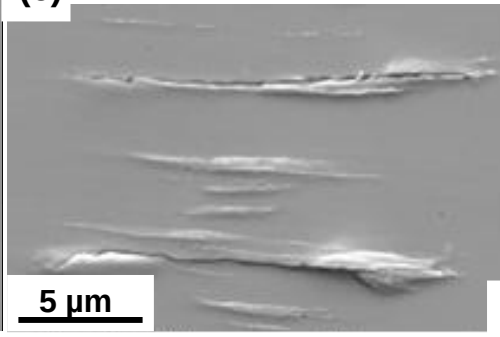

(d)

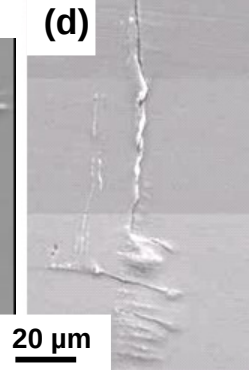

Fig. 1: Tension-compression $0^{\circ}$ oriented crack (a), torsion $\pm 45^{\circ}$ oriented cracks at nodules (b), $0^{\circ}$ and $90^{\circ}$ oriented cracks in the matrix (c and $\mathrm{d}$ respectively). The axial load is relatively vertical to the images

The distribution of crack orientation for multi-axial loads was different from that for the simple loads. For small and medium phase shifts $(\delta 0, \delta 30 \delta 60, \delta 180, \delta 150$ and $\delta 120)$, Fig. $7 \mathrm{~b}$ shows two peaks: A main peak whose maxima was located at about $+28^{\circ}$ (for $\delta<90$ ) and at about $-28^{\circ}$ (for $\delta>90$ ), with a relatively high amplitude (about $20 \%$ ); And a secondary peak whose maxima was located at about $-62^{\circ}$ (for $\delta<90$ ) and $+62^{\circ}$ (for $\delta>90$ ) and having a relatively low amplitude (about 4\%). The amplitude of the main peak increases when the phase shift decreases (far from $90^{\circ}$ ), so it was the highest for the proportional loads $(\delta 0$ and $\delta 180$ ). These distributions (of main and secondary peaks) explained the presence of non-symmetrical cross crack at nodules (cf. Fig. 9a). Cracks oriented according to the main peak were always greater than that oriented according to the secondary peak and therefore mode I crack driving force was not equal in the two directions $\left(28^{\circ}\right.$ and $\left.62^{\circ}\right)$. For the largest phase shift angles $(\delta 80, \delta 90$ and $\delta 100)$, a broad distribution of 
the crack orientation (between $-90^{\circ}$ and $90^{\circ}$ ) was observed (cf. Fig. 7b), and there was no preferred orientation of cracks (Fig. 9b).

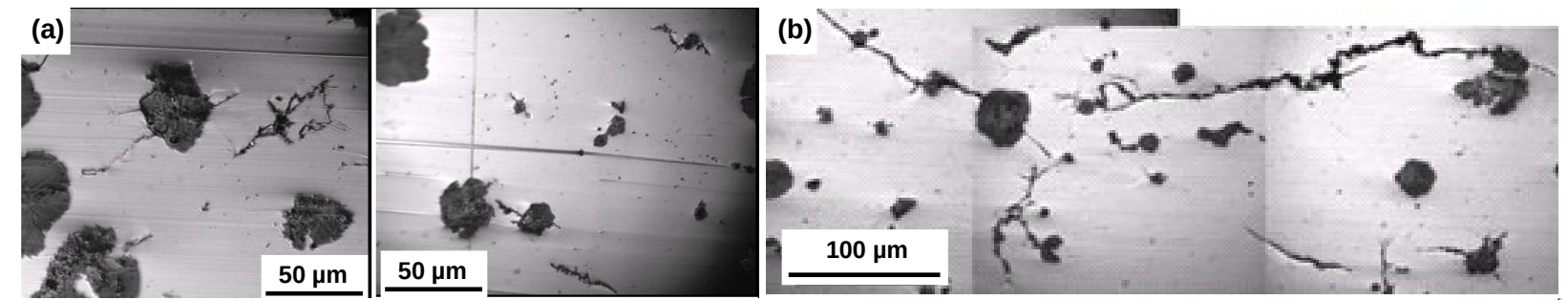

Fig. 1: Micrographs of fatigue crack orientation for $\delta 0$ and $\delta 180$ respectively (a), and $\delta 90$ (b). The axial load was relatively vertical to the images

Starting from Fig. 7a and $b$, the percentages of mode I and II cracks in function of solicitation mode could be obtained. It was determined just for simple, proportional, and small and medium phase shift, as shown in Fig. 10a. For the high phase shift, there was no specific orientation, where the cracks initiate and propagate in all directions, and it was difficult to specify the crack mode. The percentages were recorded as the sum of orientations corresponding just to mode I and / or II , so the remaining cracks (the complement to $100 \%$ ) had no defined orientation and were not counted. For simple torsion load the two crack modes were almost equivalent, whereas no mode II was observed for the other loads. The maximum fraction of mode I crack was observed for the axial load. It was found, generally, that the proportion of mode I crack decreases with increasing phase shift for multiaxial loading.

A dispersion factor $(F)$ of crack orientation could be established as follow:

$$
F=\frac{A_{R}}{S}
$$

where;

$$
S=\frac{H}{W} ; \quad A_{R}=\frac{A_{\delta x x}}{A_{\delta 90}}
$$

Where, $A_{R}$ is the area ratio of the principal peak, calculated as the area of the considered $\delta x x$ load divided by area of $\delta 90$ load (as reference). S, H and W are the slenderness, the height and the mid-width of the principal peak respectively.

The dispersion factor was maximum for the close to $\delta 90$ loads (Fig. 10b). For the other loads it still comparable and it was almost eight times inferior to $\delta 90$. This ratio ( 8 times) is close to the ratio of fatigue life (cf. Fig. 6a) between $\delta 90$ load and in-phase loads (ratio between 7 and 10).

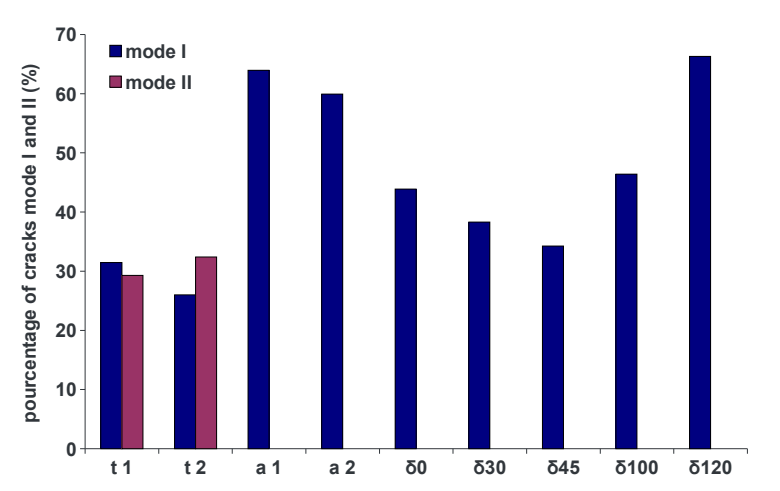

(a) load type

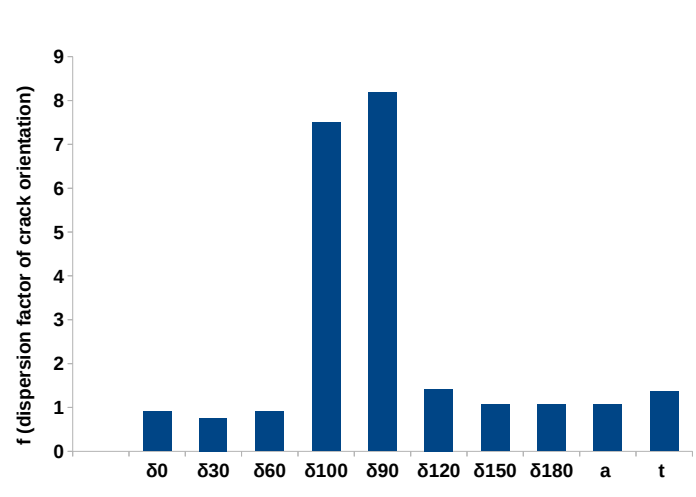

(b)

tion of mode I and / or II crack versus loading conditions

.Fig. 1: Propor-

Considering the imprecision of measure, the experimental results could not explain why the fatigue life was higher for $\delta>90$ loads than for $\delta<90$ ones (cf. Fig. 6a). They showed, indeed, that though the angular cross behavior between these symmetric loads was symmetrical relatively to $0^{\circ}$ (cf. Fig. 9a), the cross cracks were more developed for $\delta<90$ Than for $\delta>90$. FEM could therefore be necessary to assess the distribution of fatigue crack orientation and then the fatigue life shortening, and the non-symmetrical behavior of fatigue life.

\section{Finite elements analyses}


As it is seen in Fig. $5 a$ and $b$, the mean value of size and sphericity of nodules were $21.1 \mu \mathrm{m}$ and 0.53 respectively. For the sake of simplicity, a sphere modeling the nodule was impeded in a cubic matrix that modeling the nodular cast iron matrix.

The FEM was run on ABAQUS program, on a box of the ferritic matrix containing a graphite spherical nodule (Fig. 11a). Using AMIRA software, the boxes were converted into SURF format with controlled surface mesh density, then meshed automatically in tetrahedral elements (Fig. 11b). The connection between matrix and nodule was of tie constraint type. BCs at the center of nodule matrix assembly were of the displacement rotation type. Element type was C3D4: A 4-node linear tetrahedron. The model used the purely elastic property of the graphite nodule $(E=27 \mathrm{GPa}$ and $\mathrm{v}=0.22)$ and the elasto-plastic properties of the ferritic matrix $(E=207 \mathrm{GPa}$, Proof stress at $0,2 \%=275 \mathrm{MPa}$ and $\mathrm{v}=0.27$ ) obtained from tensile test (cf. Fig. 2). Isotropic hardening elastoplastic model have been applied for matrix, and no cyclic material behavior was considered. At the scale of the box, the shear component of the torsion test was assumed to be uniform (no gradient taken into account). Axial and shear displacements corresponding to a combined axial and shear strains of $0.2 \%$ and $0,35 \%$ respectively were applied on the upper and lower parts of the box. The magnitude and the direction of the principal normal $\sigma_{\text {I }}$ and shear $\sigma_{\text {II }}$ stresses and were registered at the equator of the nodule. For multi-axial load, the calculation was done at different portions ( $\beta^{\circ}$, in degrees) of half-cycle, such as $\beta=0^{\circ}, 15^{\circ}, 25^{\circ}, 45^{\circ}, 60^{\circ}, 75^{\circ}, 90^{\circ}, 05^{\circ}, 120^{\circ}, 135^{\circ}, 155^{\circ}, 165^{\circ}$ and $180^{\circ}$. Subsequently, one called the principal stresses as $\sigma_{\mathrm{I}}$ and $\sigma_{\mathrm{II}}$. The main direction $\left(\phi_{n}\right)$ was defined as the angle between the normal direction of the critical plane and the specimen axis (vertical axes). It was positive with clockwise, negative counterclockwise. $\phi_{\mathrm{n}}$ values were then in the range [-90 to $\left.+90^{\circ}\right]$.
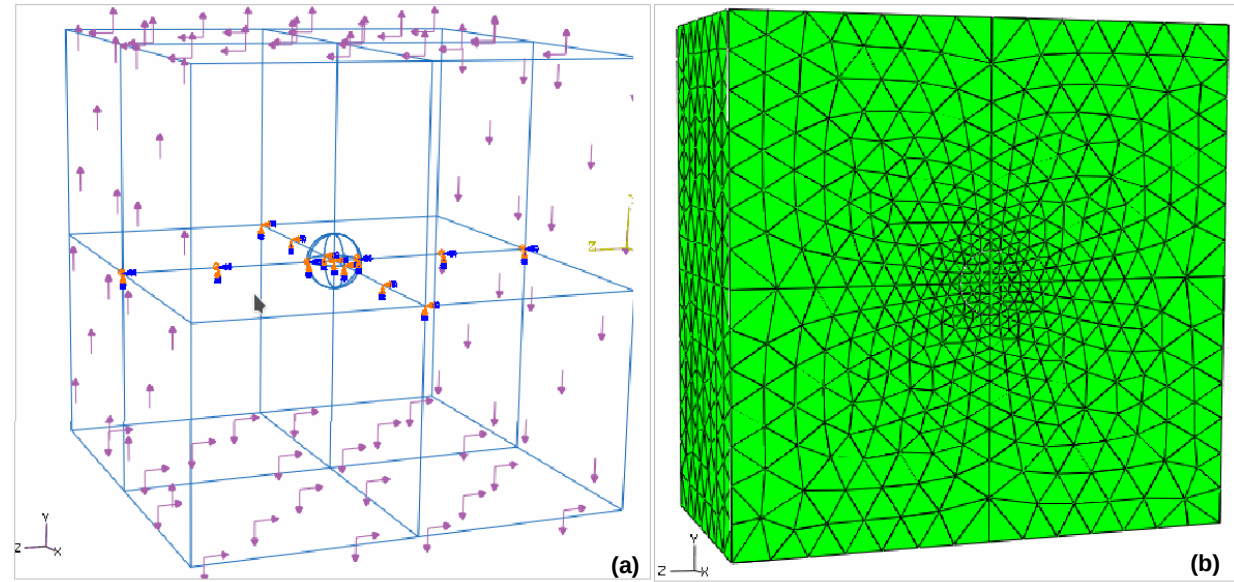

Fig. 1: (a) Finite elements model, vertical arrows represent the axial load, horizontal arrows represent the shear load. Arrows in the medium plane represent the boundary conditions, (b) meshed model cut at $\mathrm{x}=0$.

To improve the visibility of stress fields in the matrix the nodule was removed from the subsequent figures of FEM. It was found that under pure axial (Fig. 12), pure shear and proportional (Fig. 13) loads, during one-half cycle, the maximum shear and normal stresses did not change their values nor their directions, and they remain fixed. The maximum normal stress orientation $\left(\phi_{n, \max }\right)$ alternate between: $0^{\circ}$ and $90^{\circ}$ for axial load, $+45^{\circ}$ and $-45^{\circ}$ for torsion load and $28^{\circ}$ (or $-28^{\circ}$ ) and $-62^{\circ}$ (or $62^{\circ}$ ) for proportional loads. The orientations of principal stress $\left(\phi_{n, \max }\right)$ for axial, torsion and in-phase loads calculated by EFM were in agreement with the experimental crack orientations presented in Figs 7, 8, and 9a.

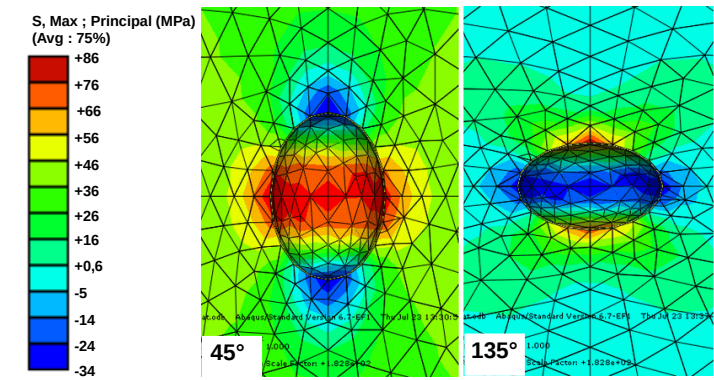

Fig. 1: Value and orientation of maximal principal stresses during one-half cycle for axial load 

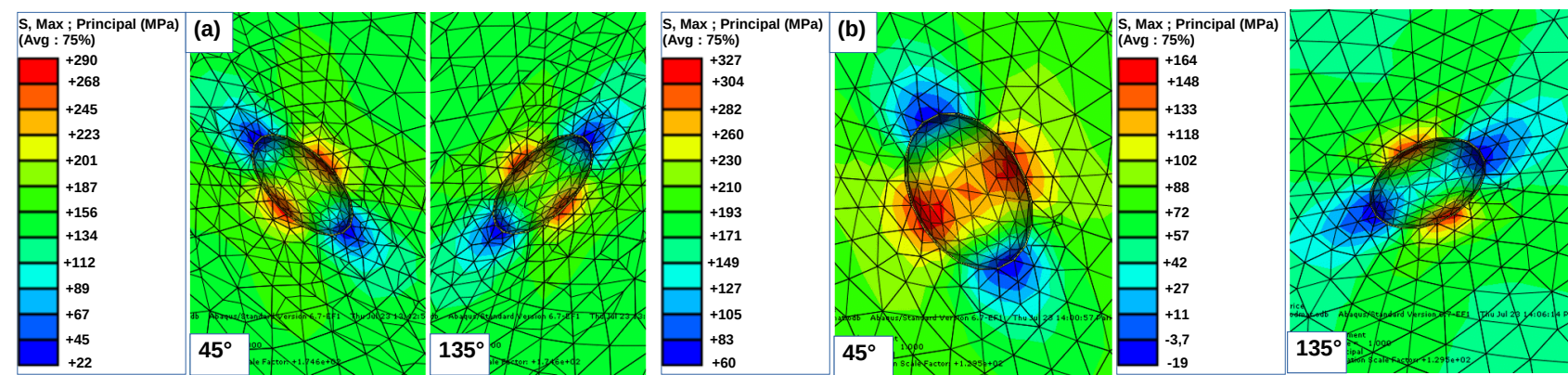

„Fig. 1: Value and orientation of maximal principal stresses during one-half cycle for shear (a) and proportional (b) loads

There were no specific orientations $\left(\phi_{n, \max }\right)$ of principal stresses for out-of-phase loads. During one-half cycle, maximum shear and normal stresses changed not only in magnitude of their value but also in their direction (Fig. 14). The orientation of principal stress for load calculated by EFM are in agreement with the experiment as showed Figs $9 \mathrm{~b}$.

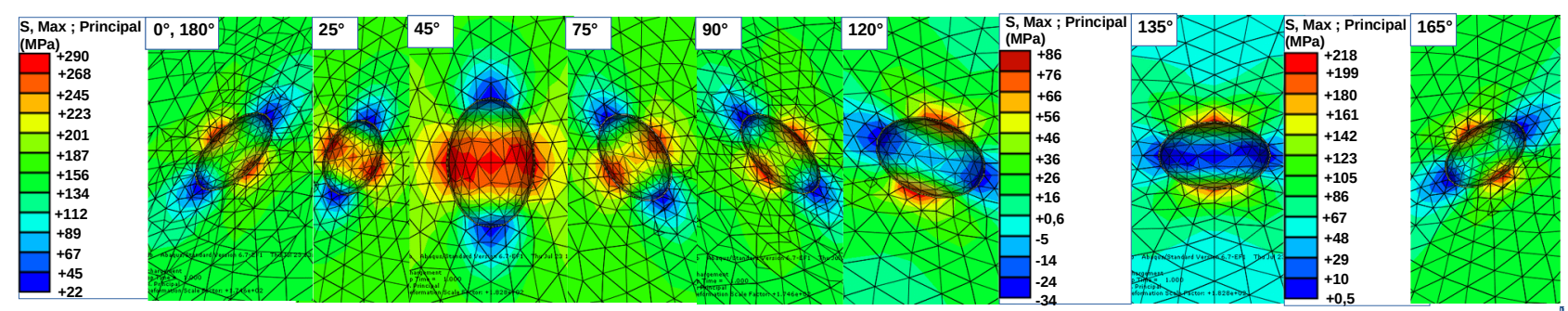

Fig. 1: Value and orientation of maximal principal stress during a one-half of the fatigue cycle for $\delta 90$

The evolution of $\sigma_{\mathrm{I}}$ value during one-half cycle was registered (Fig. 15), It was non-symmetrical between the two quarters of the one-half cycle (relatively to $\beta=90^{\circ}$ ). For non-proportional loads, a secondary peaks appeared during the unloaded quarter cycle, its position was related to the value of phase shift angle (Fig. 15). $\sigma_{\mathrm{I}}$ was higher during the loaded quarter cycle than during the unloaded half cycle. Unlike the other loads, $\sigma_{\mathrm{I}}$ for $\delta 90$ remained practically at its maximum value during a large fraction of the loaded quarter cycle. The behavior of $\sigma_{\mathrm{I}}$ for simple torsion load was also non-symmetrical relatively to $\beta=90^{\circ}$, $\sigma_{\mathrm{I}}$ was slightly higher for the unloaded quarter cycle.

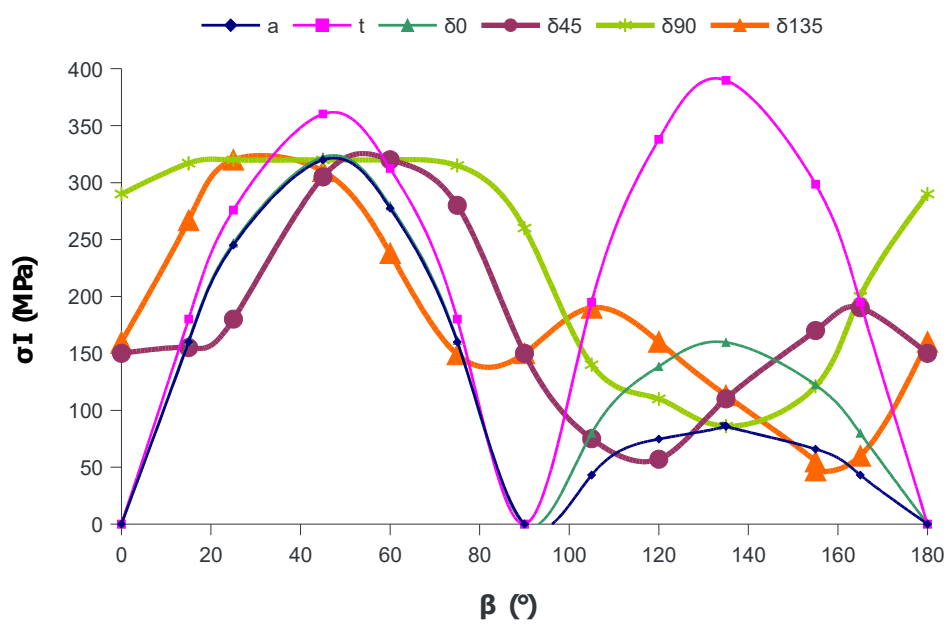

Fig. 1: Evolution of Normal principal stress value in function of loading condition during one-half cycle.

The evolutions of both $\sigma_{I}$ with $\phi_{n}$ and $\phi_{n}$ with $\beta$ were shown in Fig. $16 a$ and $b$ respectively. The nonsymmetrical behavior of crack orientation relative to $\delta=90^{\circ}$, obtained experimentally (cf. Fig. 7b) could be explained by the main directions and the values of principal stresses obtained by FEM. The direction of $\sigma_{\mathrm{I}}$ remain fixed for simple axial, torsion, and proportional loads and was reversed when the applied constraint was reversed during one-half cycle. For simple axial load, $\sigma_{\mathrm{I}}$ had a unique orientation of $0^{\circ}$ (Fig. 13), and cracks tend to initiate and propagate perpendicularly at the specimen axis (cf. Fig. 8a). For simple torsion, the two crack orientations $\pm 45^{\circ}$ matched with the two maximum values of $\sigma_{\mathrm{I}} 360$ and $390 \mathrm{MPa}$ respectively, (cf. Fig. 15), in this case, the two directions had almost, two equivalent crack driving forces. Therefore, 
cracks formed a symmetrical cross-oriented at $\pm 45^{\circ}$ from the pole and the equator of the nodule, (cf. Fig. $8 b$ ). For proportional load in the range $\delta<90$, the two orientations $-28^{\circ}$ and $62^{\circ}$ (or 28 and -62 for $\delta>90$ ) had different crack driving forces (different values of $\sigma_{\mathrm{I}}$ ), and cracking occurs primarily in the direction $-28^{\circ}$ (or 28 for $\delta>90$ ), which suffers the highest value of $\sigma_{I}$ (cf. Fig. 13b). Cracks at nodule in this case form therefore a nonsymmetrical and nonequivalent cross (cf. Fig. 9a).

The low phase shifted loads did not show fixed orientation. In agreement with the experimental results (cf. Fig. 7b), Fig. 16a shows two nonequivalent peaks, the main peak was at about $-35^{\circ}$ for $\delta<90$ (or $35^{\circ}$ for $\delta>90$ ) with high magnitude, the second was at about $55^{\circ}$ for $\delta<90$ (or $-55^{\circ}$ for $\delta>90$ ) with low magnitude. In this case, the orientation at $-35^{\circ}$ (or $35^{\circ}$ ) was most favored for cracking than for that at $55^{\circ}$ (or $-55^{\circ}$ ). FEM revealed that for the $\delta<90^{\circ}$ loads, the maximum principal stresses were applied essentially at planes of low angle $\phi_{\mathrm{n}}$ (Fig. 16b), There were then more critical planes undergoing a tensile cracks mode for $\delta<90^{\circ}$ than for $\delta>90^{\circ}$ loads, and consequently the fatigue life was reduced.

For high phase shifted loads, specially $\delta 90$, peaks disappear (cf. Fig. 16) and there was no preferred orientation of the principal plane (cf. Fig. 14). The orientation of principal plane evolute almost linearly during cycling (Fig. 16a and b) which was comparable with cracks orientation which was ranging between $-90^{\circ}$ and $90^{\circ}$ (cf. Fig. $7 \mathrm{~b}$ ). The fraction of cycle and the angular orientation for which $\sigma_{\mathrm{I}}$ was at its maximum was as high as the phase shift-angle was closer to $90^{\circ}$.
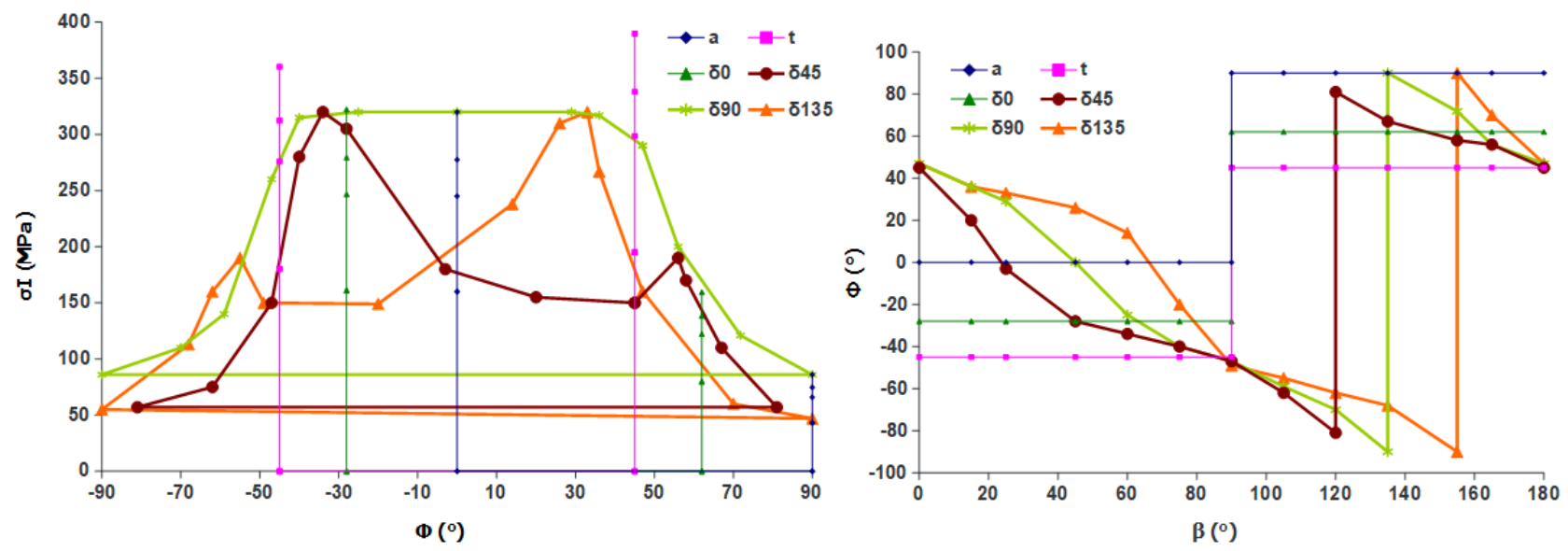

Fig. 1: (a) Evolution of $\sigma_{I}$ in function of $\phi$ and (b) Evolution of $\phi$ during one-half of fatigue cycle

The evolution of $\phi_{\mathrm{n}}$ (Fig. 16b) showed, for $\delta 90$, a quasi-linear behavior during which crack driving forces were high, while a slowing down appeared for the other phase shifted, consequently, the whole crystallographic orientations were preferential cracking orientations for $\delta 90$ load.

The two curves for $\delta<90$ (ex. $\delta 0$ and $\delta 45)$ and for $\delta>90(\delta 180$ and $\delta 135)$ had similar behavior with inverse positions of peaks (Fig. 16a) and the crack cross orientations were also the same with symmetric an gles relatively to $0^{\circ}$ (cf. Fig. 9a). However, the fatigue life in the range $\delta<90$ was about $50 \%$ lower than for $\delta>90$ (cf. Fig. 6a). This result has been explained by the non-symmetrical behavior of $\sigma_{\text {I }}$ and $\sigma_{\text {I }} / \sigma_{\text {II }}$ relative to $\delta=90^{\circ}$ (Fig. 17). Except for simple torsion, two domains were distinguished. The first (corresponding to unloaded quarter cycle) was at small values of $\sigma_{\mathrm{I}}$ and $\sigma_{\mathrm{I}} / \sigma_{\mathrm{II}}$ in this domaine, since $\sigma_{\mathrm{I}} / \sigma_{\mathrm{II}}<1$ mode II cracking was favored and crack driving force for mode I cracking was considerably reduced. The second domain (corresponding to loaded quarter cycle) was at high values of $\sigma_{\mathrm{I}}$ and $\sigma_{\mathrm{I}} / \sigma_{\mathrm{II}}$; and the crack driving force and mode I crack were then determinant for the fatigue life. In this domain, there were several behaviors. In simple torsion the ratio $\sigma_{\text {I }} / \sigma_{\text {II }}$ was almost fixed between 1 and 1.5 , originating an equilibrium between modes I and II crack (cf. Fig. 10a). Therefore mode II cracks were found in the matrix (cf. Fig. 8c and d), and mode I cracks were observed at nodules (cf. Fig. 8b). For this load, the values of of $\sigma_{\mathrm{I}}$ and $\sigma_{\mathrm{I}} /$ $\sigma_{\text {II }}$ for the two-quarters of the cycle were comparable and the observed mode I cross cracks at nodule was symmetrical and equivalent (cf. Fig. 8b). For proportional loading, due to $\sigma_{\mathrm{I}}$ and $\sigma_{\mathrm{I}} / \sigma_{\mathrm{II}}$ were nonequivalent for the two quarters of cycle, the two crack lengths of cross crack at nodules were not equivalent (cf. Fig. 9a), and mode II crack in the matrix was rarely observed. Simple axial load, which present the highest values of $\sigma_{\text {I }} / \sigma_{\text {II }}$ (about 4.2), favors mode I crack (cf. Fig. 10a). For $\delta 90, \sigma_{I}$ and $\sigma_{\text {I }} / \sigma_{\text {II }}$ preserve a maximum value during a large fraction of fatigue cycle, and therefore the fatigue life was shortened.

For symmetrical multi-axial loads according to $\delta 90$, the fractions of fatigue cycle, for which $\sigma_{\mathrm{I}}$ and $\sigma_{\mathrm{I}} /$ $\sigma_{\text {II }}$ were maximums were not equivalent for the symmetric loads. This fraction was higher for $\delta<90^{\circ}(\delta 0$, $\delta 45 \ldots)$ than for $\delta>90^{\circ}(\delta 180, \delta 135 \ldots)$, then the stress concentration in front of the crack was higher for $\delta$ 
$<90^{\circ}$. Crack growth and crack driving force could consequently be higher (cf. Fig. 9a, crack cross was more developed for $\delta 0$ than for $\delta 180$ ), causing a lower fatigue life for $\delta<90^{\circ}$ (cf. Fig. 6a).
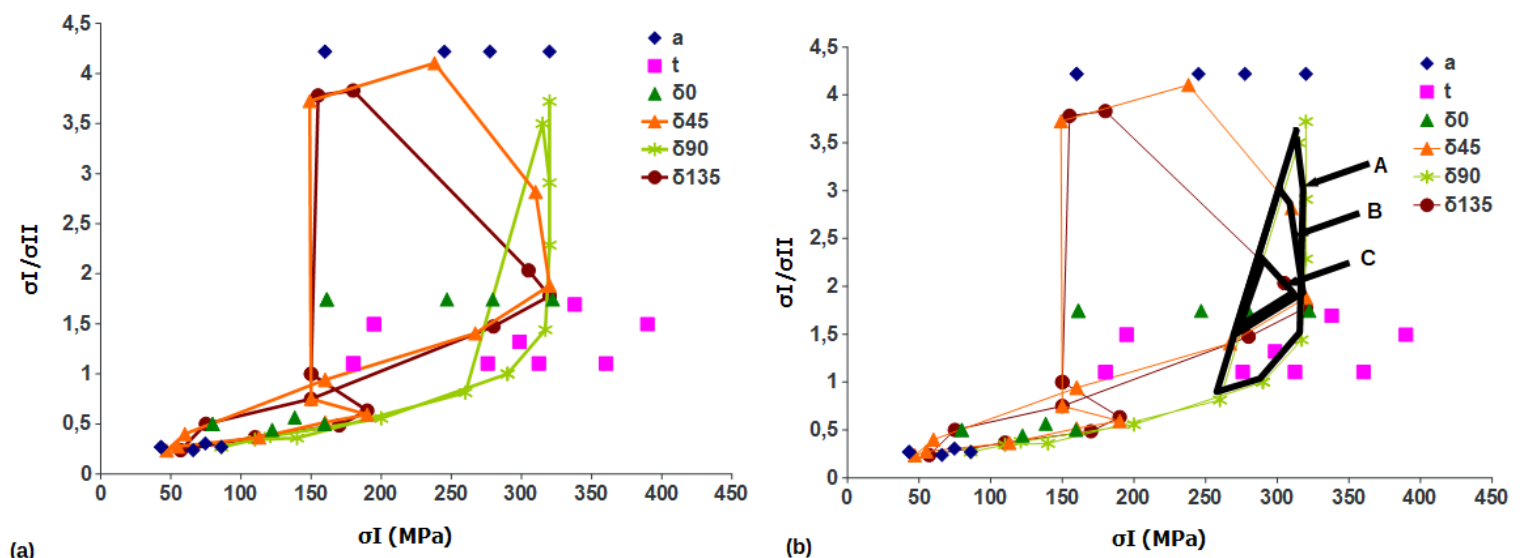

Fig. 17: $\sigma_{\mathrm{I}}$ versus $\sigma_{\mathrm{I}} / \sigma_{\mathrm{II}}$ for the different loads types

FEM seemed adequate to explain the non-symmetrical behavior of fatigue life relative to $\delta=90$. In fact, the fraction of fatigue cycles for which crystallographic planes undergo maximum principal stress was higher for $\delta<90^{\circ}$ than for $\delta>90^{\circ}$. FEM revealed that for the $\delta<90^{\circ}$ loads, the maximum principal stresses were applied essentially at planes of low angle $\phi$ for $\delta>90^{\circ}$ (Fig. 17b), so there were more of planes undergoing a tensile cracks mode for $\delta<90^{\circ}$ than for $\delta>90^{\circ}$ loads, consequently the fatigue life was reduced.

In Fig. $17 \mathrm{~b}, \delta 90^{\circ}$ load was considered as a reference load where all critical planes undergoes the maximum principal stress, and the values of $\sigma_{\mathrm{I}}$ and $\sigma_{\mathrm{I}} / \sigma_{\text {II }}\left(\right.$ for $\delta 90^{\circ}$ ) which governed the fatigue life are delimited by the area $A$ (defined as in the figure). Of the same and relatively to $\delta 90$ reference load, the homologous values of $\sigma_{\mathrm{I}}$ and $\sigma_{\mathrm{I}} / \sigma_{\mathrm{II}}$ for $\delta 45$ et $\delta 135$ loads were delimited by the areas $\mathrm{B}$ and $\mathrm{C}$ respectively. The value of each area was calculated as the sum of several triangles and rectangles. These calculations allowed establishing the ratios between the three areas as follow:

$$
\frac{B}{A}=0,455, \frac{C}{A}=0,2
$$

Of the same, one defined the numbers of critical directions undergoing a principal direction as $a, b$ and $c$ for the three loads $\delta 90, \delta 45$ and $\delta 135$ respectively. The ratios (a as reference) of these numbers were proportional to the area ratios $A, B$, and $C$ respectively, i.e:

$$
\frac{b}{a}=0,455 \quad, \frac{c}{a}=0,2
$$

The number of critical planes undergoing the maximum principal direction was a function of the outof-phase angle $\delta$, and could be expressed as the fraction $f(\delta)$ of critical planes undergoing maximum principal stress, where $f(\delta) \leq 1$.

Tacking $\delta 90^{\circ}$ load as reference, one obtained: $f(\delta)_{90}=1, f(\delta)_{45}=0.455, f(\delta)_{135}=0.2$. The critical planes undergo then principals planes during a fraction of cycle which was higher for $\delta<90^{\circ}$ than for $\delta>$ $90^{\circ}$.

One could establish a qualtitative comparison between these ratios and the ratios of fatigue life (obtained from Fig. 6a) between these three loads:

$$
\frac{N r(\delta 90)}{N r(\delta 135)}=\frac{37500}{221000}=0,17 \quad \frac{N r(\delta 90)}{N r(\delta 45)}=\frac{221000}{350000}=0,11
$$

Although it was difficult to establish a quantitative relation between $f(\delta)$ and the ratios of fatigue life, this procedure could relate qualitatively the fatigue life to the out-of-phase angle..

\section{Disscussion}


The distribution of crack orientation in nodular graphite cast iron subjected to simple (axial, torsion), proportional and non-proportional cyclic loadings was studied. The experimental results were supported and explained by FEM. The experimental results showed essentially a non-symmetrical behavior of the fatigue life relatively to $\delta=90^{\circ}$ : It was higher for phase shifts situated in the range $90<\delta<180$ than for symmetrical angles in the range $0<\delta<90$. The numerical method could explain this non-symmetrical behavior by revealing a non-symmetrical behavior of $\sigma_{\mathrm{I}}$ and $\sigma_{\mathrm{I}} / \sigma_{\mathrm{II}}$ relatively to $\delta=90^{\circ}$. The critical planes oriented at low angle $\phi_{\mathrm{n}}$ (near to $0^{\circ}$ ) underwent a more tensile crack mode. FEM revealed that the fraction of planes that underwent the principal directions (a tensile cracks mode) was higher for the $\delta<90^{\circ}$ loads, a tensile crack mode was then more dominating for $\delta<90^{\circ}$ than for $\delta>90^{\circ}$ loads, consequently the fatigue life was reduced.

Cracks stayed oriented at two specific orientations for the far to $\delta 90$ loads $\left(0^{\circ}, 30^{\circ} 150^{\circ}\right.$ and $\left.180^{\circ}\right)$ loads, but the cracks distribution at these orientations was not equal due to the difference of the principal stress magnitude $\left(\sigma_{\mathrm{I}}\right)$ mentioned by the numerical method. A large phase shift (close to $90^{\circ}$ ) broaden the distribution of fatigue crack orientation to be located in the interval $\left[-90^{\circ}\right.$ to $\left.+90^{\circ}\right]$, and no specific, or ran dom, crack orientation was observed, which shorten the fatigue life. A factor of distribution (F) of crack orientation was proposed, which was very high ( 8 time) for the close to $\delta 90$ than for the far to $\delta 90$ loads. This ratio (8) corresponded to the fatigue life ratio between the $90^{\circ}$ out-of-phase and the in-phase loads (ratio between 7 and 10). It was found that the distribution of crack orientation was similar to that of $\sigma_{\mathrm{I}}$ orientation. Therefore, it was rational to define both the plane where the fatigue crack grows and the plane of maximum normal stress as the same critical plane, when both coincide. The number of critical planes undergoing the maximum principal direction could be expressed as the fraction $f(\delta)$ of critical planes undergoing maximum principal stress, where $f(\delta) \leq 1$, it was 1 for $\delta 90$, and higher for $\delta<90^{\circ}$ than for $\delta>90^{\circ}$. The ratio $\sigma_{\mathrm{I}} / \sigma_{\mathrm{II}}$ was also determining the crack mode, consequently the fatigue life. Experimental and numerical methods showed that cracks orientation and location $\phi$ and principal plane orientation $\phi_{n, \max }$ respectively depend on the multi-axial loading conditions, and there were four distinct behaviors:

- Axial loading; $\phi=\phi_{n, \max }=0^{\circ}$, cracks located at nodules (mode I).

- Torsion loading; $\phi=\phi_{n, \max }= \pm 45^{\circ}$, cracks located at nodules (mode I) (driving force was equal in the two directions $\left( \pm 45^{\circ}\right)$ ), and at $0^{\circ}$ and $90^{\circ}$ in the matrix (mode II).

- Proportional and non-proportional loadings: $\phi=\phi_{n, \max }=-28^{\circ}$ and $+62^{\circ}$ or $+28^{\circ}$ and $-62^{\circ}$ (driving force not equal in the two direction), cracks located at the nodules for $\delta>90^{\circ}$ and $\delta<90^{\circ}$ respectively.

- Non-proportional loading with $\delta \approx 90^{\circ}: \phi=\phi_{n, \max }=\left[-90^{\circ}\right.$ to $\left.+90^{\circ}\right]$, cracks located in the matrix.

The results showed also the profitable effect of the negative principal stress $\sigma_{\text {II }}$ in torsion which increase the fatigue life (lifetime over 4 million cycles). Mode II crack was observed in the matrix when $\sigma_{\text {I }} / \sigma_{\text {II }}$ was close to 1 , whereas it was not observed for high phase shift loads where $\sigma_{\text {I }} / \sigma_{\text {II }}$ was higher.

The determination of the crack mode becomes more and more difficult with increasing phase shift; therefore, crack mode had been experimentally determined for simple, proportional and low phase shifted loadings, and not for high phase shift angle load. Even when the applied loads was predominantly torsion, the damage was observed to occur, equally, along the maximum principal stress planes (at nodules) and shear planes (in the matrix); in fact, the stress concentration at nodules gave privileges to the mode I crack to the detriment of the mode II one. For high phase shift angle (close to $90^{\circ}$ ), it was suggested that only mode I crack dominated the initiation and propagation phases of cracks, and that their proportion could reach $100 \%$. In this case the cracks orientation study could not be valuable to determine the proportion of mode I propagating cracks. When $\sigma_{\mathrm{I}}$ increases, the stress intensity factor (SIF) in the crack tip and at nodules increase. This maximum concentration appears periodically for small phase shift loading, and remain constant during the whole fatigue cycle for high phase shift angles. It was assumed that this produces a lower fatigue limit because the crack driving force was nearly equal in all directions, thus allowing cracks to link up weaker regions of the complex cast iron microstructure.

\section{Conclusion}

The study showed a good correlation between the experiment and the FE method. In fact, the numerical method was capable to explain the reduction of fatigue life when the phase shift evolute from $0^{\circ}$ or $180^{\circ}$ to $90^{\circ}$ and the nonsymmetric behavior of both fatigue life and the distribution of crack orientationrelatively to $\delta=90^{\circ}$. FEM showed that the planes oriented at low angle $\phi_{\mathrm{n}}$ underwent a more tensile crack mode. FEM revealed that for the $\delta<90^{\circ}$ loads, the maximum principal stresses were applied essentially at critical planes of low angle $\phi$, so there were more planes undergoing a tensile cracks mode for $\delta<90^{\circ}$ than for $\delta>90^{\circ}$ loads, and consequently the fatigue life was significantly reduced. The numerical model represents than a good tool to study other type of multi-axial loads or other materials with inclusions or crystalline defects. 


\section{Acknowledgment}

The first author thanks AUF (Agence universitaire de la francophonie), PAUSE (Programme national d'aide à l'Accueil en Urgence des Scientifiques en Exil) program, Scholar Rescue Fund (SRF) and the personnels of INSA Lyon and MATEIS-METAL for the scholar rescue supports.

\section{References}

[1] Claudio B., Cianetti F. An equivalent uniaxial stress process for fatigue life estimation of mechanical components under multi-axial stress conditions. Int J Fatigue 2008;30:1479-1497.

[1] Yanyao Jiang Y. Hertel O. and al. An experimental evaluation of three critical plane multi-axial fatigue criteria. Int J Fatigue 2007;29:1490-1502.

[1] Mohta K. Gupta S. and al. Fatigue damage assessment under multi-axial non-proportional cyclic loading, conference proceedings, $7^{\text {th }}$ international conference on creep, fatigue and creep-fatigue interaction, igcar, kalpakkam, india, keshav mohta and al. 2016:19-22.

[1] Papuga J. A survey on evaluating the fatigue limit under multi-axial load. Int J Fatigue 2011;33;2:153165.

[1] Allaoui A. Taleb L. and al. Fatigue of Extruded 2017A Aluminum Alloy Subjected to non-proportional Loading Paths, Key Engineering Materials, Main Theme Advances in Engineering Plasticity and its Application XIII, Edited by: Fusahito Yoshida and Hiroshi Hamasaki. 2017;725:334-338.

[1] Dumitru I., Kun L. and al. The equivalent stress concept in multi-axial fatigue, Journal of Engineering Studies and Research. 2011;17;2:53-62.

[1] Bishop, N.W.M., Sherrat, F. Finite element based fatigue calculations, NAFEMS Ltd. 2000.

[1] Surajit K. P. Prediction of non-proportional cyclic hardening and multi-axial fatigue life for FCC and BCC metals under constant amplitude of strain cycling, Materials Science and Engineering 2016;A656:111-119.

[1] Fatemi A. Shamsaei N. multi-axial fatigue: An overview and some approximation models for life estimation. Int J Fatigue 2011;33;8:948-958.

[1] Gates N.R. Fatemi A. A simplified cyclic plasticity model for calculating stress-strain response under multi-axial non-proportional loadings, European Journal of Mechanics - A/Solids 2016;59:344-355.

[1] Carpinteri A. De Freitas M. and al. Biaxial/multi-axial fatigue and fracture. Elsevier - Technology \& Engineering 2003:516 pages.

[1] Zhao T. Jiang Y. Fatigue of 7075-T651 aluminum alloy. Int J Fatigue 2008;30;5:834-849.

[1] Hoffmeyer J. Döring R. and al. Deformation behavior, short crack growth and fatigue lives under multiaxial non-proportional loading; Int J Fatigue 2006;28:508-520.

[1] Endo M. Iseda K. Prediction of the fatigue strength of nodular cast irons under combined loading. Int J of Modern Physics 2006;20;25n27:3817-3823.

[1] Socie DF.. Waill L.A., Dittmer D.F. Biaxial fatigue of Inconel 718 including mean stress effects. In: Miller KJ, Brown MW, editors. multi-axial fatigue, ASTM STP 853, 1985:63-81.

[1] Zhang J. Jiang Y. Fatigue of polycrystalline copper with different grain sizes and texture. Int J Plast 2006;22:536-56.

[1] Sonsino C.M. Influence of material's ductility and local deformation mode on multi-axial fatigue response. Int J Fatigue 2011;33;8:930-947.

[1] Jiang Y, Feng M. Modeling of fatigue crack propagation, J. Eng. Mater. Technol 2004;126;1:77-86.

[1] Jiang Y. A fatigue criterion for general multi-axial load. Fatigue Fract Eng Mater Struct 2000;23:19-32.

[1] Endo M. Hashimoto I. The fatigue strength of steels containing small holes under out-of-phase combined loading. Int J Fatigue 2006;28:592-597.

[1] Zerres P. Vormwald M. Review of fatigue crack growth under non-proportional mixed-mode loading. Int ] Fatigue 2014;58:75-83.

[1] Shang D.G. Sun G.Q. and al. multi-axial fatigue damage parameter and life prediction for medium-carbon steel based on the critical plane approach. Int J Fatigue 2007;29:2200-2207.

[1] Marquis G.B. Karjalainen-Roikonen. P. Long-life multi-axial fatigue of a nodular graphite cast iron, Biaxial/multi-axial Matigue and Fracture, Andrea Carpinteri, Manuel de Freitas and Andrea Spagnoli (eds.), 2003:105-122.

[1] Kouhia R. Brief introduction to continuum mechanics, Lecture notes to the course Mechanics of materials, Tampere University of Technology, Tampere, Finland, Laboratory of Civil Engineering. 2016:99 pages.

[1] Brown M. W. Miller, K. J. Mode I fatigue crack growth under biaxial stress at room and elevated temperature, In: multi-axial Fatigue, ASTM STP 853, K. J. Miller and M. W. Brown (Eds.), ASTM, Philadelphia, 1985:135-152. 
[1] Ting S. Ren-bo S. and al. Microstructure and phase transformation of wear resistant ductile iron grinding balls by continuous cooling process. Materials Science \& Engineering 2015;A626:375-381.

[1] Tovo R. Lazzarin P. Berto F. Cova M. Maggiolini E. Experimental investigation of the multiaxial fatigue strength of ductile cast iron. Theorical and Applied Fracture Mechanics. 2014; 73; 60-67. 